\title{
Agôn
}

Revue des arts de la scène

Critiques | Saison 2009-2010

\section{Si ce n'est toi, ou comment Alain Françon parvient à rendre à la pièce d'Edward Bond ses lettres de noblesse}

À propos de Si ce n'est toi d'Edward Bond mis en scène par Alain Françon

\section{Antoine Amblard}

\section{OpenEdition}

\section{Journals}

Édition électronique

URL : http://journals.openedition.org/agon/582

DOI : 10.4000 /agon.582

ISSN : 1961-8581

Éditeur

Association Agôn

Référence électronique

Antoine Amblard, «Si ce n'est toi, ou comment Alain Françon parvient à rendre à la pièce d'Edward

Bond ses lettres de noblesse », Agôn [En ligne], Critiques, mis en ligne le 05 février 2008, consulté le 23 septembre 2020. URL : http://journals.openedition.org/agon/582 ; DOI : https://doi.org/10.4000/agon. 582

Ce document a été généré automatiquement le 23 septembre 2020.

Association Agôn et les auteurs des articles 


\title{
Si ce n'est toi, ou comment Alain Françon parvient à rendre à la pièce d'Edward Bond ses lettres de noblesse
}

À propos de Si ce n'est toi d'Edward Bond mis en scène par Alain Françon

\author{
Antoine Amblard
}

1 Le futur a toujours fait rêver et permis aux auteurs, metteurs en scène et réalisateurs d'imaginer des mondes post-apocalyptiques ou merveilleux selon leur vision du monde d'aujourd'hui. Si ce n'est toi d'Edward Bond dépeint un futur répressif totalitaire en 2077 où la préservation de l'intimité est difficile, voire impossible. Mis en scène par Alain Françon, Si ce n'est toi a été représenté cette année les $1^{\text {er }}$ et 2 Avril au Toboggan, Centre culturel de Décines.

2 2077. Une femme, Sara, assise sur une chaise, semble attendre quelque chose. On frappe à la porte, elle ouvre. Personne. Son mari, Jams, revient de son travail et lui raconte une histoire de vieille dame qu'elle n'écoute qu'à moitié. Puis un homme arrive. Il prétend être le frère de Sara. Dehors, la population est touchée par un mal inconnu qui rend les habitants inexpressifs dont certains finissent par s'entretuer. La conversation tourne à la dispute entre Jams et Sara, arbitrée par Greg. Une dispute incohérente à propos de leurs chaises respectives...

3 Le décor est simple : un espace fermé ressemblant à une salle de séjour, une porte donnant accès à la rue, un couloir menant à la cuisine. Une table et deux chaises noires au centre de la scène. Un mobilier succinct mais qui joue un rôle majeur puisque c'est autour de lui que nos trois personnages vont et viennent durant toute la pièce. Cet espace nous donne tout de suite l'ambiance du spectacle. Voyeur, le public assiste à un moment tragi-comique dans la vie d'un couple. Une vie qui parait lisse et sans saveur.

4 Le parti pris du metteur en scène concernant les sonorités respecte fidèlement la pièce d'Edward Bond. Le silence de la première scène est pesant, gênant, et semble durer une éternité. Puis on frappe à la porte, et là, le temps s'arrête, notre cœur bat la chamade, 
comme celui qu'on croit entendre depuis l'extérieur. Qui est cet individu qui perturbe le quotidien de Sara? On est inquiets, surtout qu'il n'y a personne derrière la porte quand Sara se décide et va ouvrir.

5 L'aisance corporelle de la comédienne Dominique Valadié, qui joue le personnage de Sara, est impressionnante. Ses déplacements, furtifs, aériens, conséquence d'une terreur quotidienne, sont poignants et criants de vérité. Quel contraste avec le comédien Luc-Antoine Diquero, qui interprète le rôle de Jams. La démarche du comédien est assurée, ancrée au sol, témoignant de la psychologie de son personnage, un résistant sans scrupules.

6 Quand au troisième comédien, Abbès Zahmani, il joue un Greg assez simplet qui crée un décalage tordant avec les deux autres personnages plutôt pathétiques. Il essaie tant bien que mal de se faire une place dans la vie de Sara en se faisant passer pour son frère, pour découvrir à la fin qu'il est un imposteur ou que le mal extérieur s'est emparé de lui...c'est au spectateur de décider.

7 Ce qui surprend le plus, après lecture de la pièce d'Edward Bond juste avant de voir la mise en scène d'Alain Françon, c'est l'humour qu'on ne perçoit pas forcément quand on lit la pièce. Les scènes de dispute absurdes à propos des objets présents sur scène - la chaise de Sara, celle de Jams et le sac de Greg - sont irrésistibles.

8 Comédie, drame, tragédie, Si ce n'est toi explore avec beaucoup de crédibilité et de sincérité un brouillage de genres parfaitement maîtrisé. Le spectateur est surpris de passer du rire à la pitié devant ce couple qui est progressivement envahi par le mal extérieur...Jusqu'à la scène finale où Sara décide de s'empoisonner à la place de son « frère » et souffre de façon grotesque. Une scène dans laquelle Jams réagit de manière intolérable, donnant plus envie au public de sourire tant la scène paraît surréaliste.

9 Il est difficile d'être surpris quand on connait le théâtre de l'absurde, où dès le départ les codes sont donnés: personnages bizarres, dialogues incohérents, évènements spectaculaire...De nombreux auteurs comme Eugène Ionesco ou Samuel Beckett savent nous embarquer dans des univers décalés...Mais Edward Bond réussit en plus à nous surprendre par des genres apparaissant là où on ne s'y attend pas. La mise en scène d'Alain Françon est une représentation fidèle de l'univers intimiste et fragile de la pièce, où tout semble sur le fil et prêt à s'écrouler.

\section{AUTEUR}

\section{ANTOINE AMBLARD}

Étudiant en deuxième année de Licence Arts du spectacle, Université Lumière - Lyon 2 